\title{
Numerical Simulation of Meteorological Conditions and Air Quality above Tomsk, West Siberia
}

\author{
Alexander Starchenko ${ }^{1,2}, *$, Elena Shelmina ${ }^{1,3}$ and Lubov Kizhner ${ }^{1}$ \\ 1 Laboratory of Computational Geophysics, National Research Tomsk State University, 634050 Tomsk, Russia; \\ eashelmina@mail.ru (E.S.); kdm@mail.tsu.ru (L.K.) \\ 2 V.E. Zuev Institute of Atmospheric Optics, Siberian Branch of the Russian Academy of Sciences, \\ 634055 Tomsk, Russia \\ 3 Faculty of Computer Systems, Tomsk State University of Control Systems and Radioelectronics, \\ 634055 Tomsk, Russia \\ * Correspondence: starch@math.tsu.ru
}

Received: 8 September 2020; Accepted: 20 October 2020; Published: 23 October 2020

\begin{abstract}
This paper presents the simulation results of meteorological and air quality parameters for the Siberian city of Tomsk predicted by mesoscale meteorological and chemical transport models. Changes in the numerically predicted wind velocity fields, temperature, and concentration of major air pollutants were modelled in detail for the selected dates, when anticyclonic weather with cloud free and calm wind conditions was observed in Tomsk. The simulation results have shown that stable or neutral atmospheric stratification with light wind and low ambient air temperature $(-30$, $-20^{\circ} \mathrm{C}$ ) are the most unfavorable meteorological conditions leading to the near surface pollutants accumulation. The numerical calculation results were compared with observation data from the Joint Use Center (JUC) "Atmosphere" of V.E. Zuev Institute of Atmospheric Optics (IAO) and showed good agreement.
\end{abstract}

Keywords: mathematical modeling; air pollution; cold winter; numerical prediction of air quality

\section{Introduction}

Atmospheric air quality in cities depends on many factors in the modern world. An air pollution occurs as a result of both natural processes and human activity. Humans play an increasing role in air pollution. Most of the air pollution is caused by the combustion of hydrocarbon fuels during electrical energy production and operation of vehicle engines. In addition, a certain contribution to air pollution is provided by the urban "heat island," which is typical for megalopolises, especially in cold months [1].

The main reason for the air temperature increase in a city is anthropogenic transformations of the earth's surface. Dense urban development, covering natural surface with materials that actively absorb heat radiation, and reducing the area occupied by green spaces leads to changes in the thermal properties of the earth's surface and reduces total evaporation [1].

In addition, many recent studies notified the influence of temperature or a season of the year on air quality. Thus, the authors [2] study seasonal fluctuations in the concentration of suspended solid particles in China. The authors conducted their research with mathematical modeling, time series, and splines. They established a "seasonal" model to obtain the season-specific effect estimates of $\mathrm{PM}_{10}$ and a "harmonic" model to show the seasonal pattern that allows $\mathrm{PM}_{10}$ effects to vary smoothly with the day in a year. Based on the performed numerical calculations, it has been found that air pollution by solid particles can vary from season to season with the highest concentration of solid particles during the winter. One of the reasons for this phenomenon is that coal has been the main source of 
energy in China for a long time, and coal burning in coal-fired boilers and power plants is especially common in winter for heating and, in summer, for cooling.

The article [3] assesses the influence of meteorological conditions on the variability of the concentration of sulfur dioxide and solid particles in Poland during winters. The analysis covers calendar winters (December-February) within the period between 2004/2005 and 2009/2010. The variability of concentrations of both pollutants under various weather conditions was assessed with the help of cluster analysis. Clusters with the highest concentrations of pollutants were characterized, in most cases, by the lowest air temperature and lower wind speed, and often by higher pressure, and sometimes by slightly lower relative humidity, i.e., anticyclonic weather conditions. Weather conditions had a statistically significant effect on the concentrations of pollutants in all clusters. However, air temperature and wind speed played a crucial role. For example, adverse anticyclonic weather conditions observed in January 2006 had a significant impact on the concentrations of gaseous pollutants, whereas, in July, they had a stronger effect on tropospheric ozone and solid particles. The authors of this work came to the conclusion that air quality primarily depends on air temperature and wind speed.

The research [4] represents the results of the passive substance transport modeling in Krasnoyarsk city (East Siberia, Russia) during warm and cold periods. The calculations are based on the mesoscale non-hydrostatic model. The purpose of the research was to study the features of mesoclimate formation in Krasnoyarsk, describe typical meteorological conditions, and assess their impact on the accumulation of pollutants in the urban atmosphere. The authors focus on meteorological scenarios with low wind speed since such conditions are most unfavorable in terms of the accumulation of pollutants in the lower atmosphere. They compare scenarios of the pollutants' distribution from emissions from elevated point sources under these conditions. Numerical experiments have shown that these type of emissions do not significantly affect the accumulation of pollutants in the surface layer either in the winter or in the summer.

The article [5] represents an assessment of the relationship between meteorological parameters and concentrations of air pollutants in Poland in the winter time. This analysis includes daily concentrations of pollutants and changes in meteorological parameters (wind speed, air temperature, relative humidity, and precipitation) in certain months of the winter period (November-April 2005-2009). The influence of meteorological parameters on the concentration of the analyzed pollutants was determined by correlation and regression analysis. The authors note that the maximum concentration of pollutants $\mathrm{NO}, \mathrm{NO}_{2}, \mathrm{NO}_{\mathrm{X}}$, and $\mathrm{SO}_{2}$ is observed in the coldest winter months (January, February, and December). In addition, it was noticed that the concentration of gaseous and dust pollutants mainly depends on wind speed among the estimated meteorological factors. An increase, therefore, led to a decrease in the concentration of air pollution. The total solar radiation, relative humidity, and temperature had a significantly lower impact on air quality.

The research presented in the article [6] suggests that Lanzhou, a typical valley-type city in Northwestern China, is exposed to severe air pollution. However, the pathways of pollutant transport from local emissions outside the valley are still unclear. The authors of this article analyzed meteorological parameters and concentrations of pollutants over Lanzhou with the WRF-FLEXPART model during six winters from 2002 to 2007 . It was found that mountain-valley winds and the "heat island" effect are two important factors.

Therefore, the review shows that meteorological factors are important in atmospheric pollution. Weather patterns determined by the large-scale synoptic condition are different in different regions and depend on the type of climate, terrain, landscape (urban or rural), and underlying surface (land or water).

One of the main meteorological factors influencing atmospheric air quality is the near ground wind speed value in the continental climate conditions typical for the Siberian region and Tomsk city in the cold season. High pollution levels were observed at $10 \mathrm{~m}$ wind speeds of no more than $2 \mathrm{~m} / \mathrm{s}$. Other factors include temperature and its vertical distribution, air humidity, and particular features of atmospheric circulation associated with the "heat island" effect. In addition, the capacity of 
thermal power plants that burn coal or hydrocarbon fuel significantly increases in the cold season at air temperatures of about -30 to $-20^{\circ} \mathrm{C}$.

The purpose of this work is to test and apply the developed mesoscale model of atmospheric air quality $[7,8]$ for the Siberian region in order to determine the most unfavorable meteorological conditions at low ambient temperatures that lead to the accumulation of pollutants near the earth's surface where the main human activity occurs.

In this paper, the model is applied to the city of Tomsk $\left(56.5^{\circ} \mathrm{N}, 85^{\circ} \mathrm{E}\right)$ and suburban territories. Tomsk is the oldest city in Siberia, the center of the Tomsk region, which is an educational, scientific, and cultural city with a population of about 800,000 people. It is located in the East of Western Siberia on the Tom River. The climate is transitional from the European temperate continental to the Siberian sharply continental region with extreme temperatures of $-55^{\circ} \mathrm{C}$ in January and $+35^{\circ} \mathrm{C}$ in July.

The terrain of the city and surrounding areas is not uniform. The city is located mainly on the elevated right bank of the Tom River, $60 \mathrm{~km}$ from its influx into the Ob River. The central part of the city is located at an altitude of approximately $120 \mathrm{~m}$ above sea level. The terrain rises to the East merging with the spurs of Kuznetsk Alatau and Salair Ridge (altitude up to $170 \mathrm{~m}$ ). The left bank of the Tom River (the Western suburbs of the city) has an altitude of 80-110 m.

Vegetation in the suburbs is diverse. Taiga and forest-steppe zones converge here. Large woodlands around the city (aspen, birch, fir, cedar, pine) cause significant macro-roughness of the surface, which contributes to a certain decrease in wind speed as compared to an open area.

Temperature transition through $0^{\circ} \mathrm{C}$ is observed in April and October. The average date of snow cover melting is 28 April. The average date of stable snow cover formation is 30 October. The heating period lasts from 1 October to 1 May every year.

Differences in altitudes and land forms in various districts of the city and its suburbs, the presence or absence of forest vegetation, and the orientation of the Tom River valley affect the climate of the corresponding areas of the city, and primarily their temperature and wind patterns.

The Tom River freezes on average in late October-early November and breaks up at the end of April. The average duration of freezing-up is 158-160 days. The river is free of ice for 175 days a year.

\section{Materials and Methods}

The non-stationary Eulerian chemical transport model (CTM) was used to calculate the formation and dispersion of pollutants in the atmosphere of Tomsk. The governing equations, along with the non-stationary term, contain terms that represent horizontal and vertical advection and turbulent diffusion, wet deposition, and source terms that model the emissions of primary air pollutants and their chemical reactions [8].

$$
\begin{gathered}
\frac{\partial C_{i}}{\partial t}+\frac{\partial U C_{i}}{\partial x}+\frac{\partial V C_{i}}{\partial y}+\frac{\partial W C_{i}}{\partial z}=\frac{\partial}{\partial x}\left(K_{x y} \frac{\partial C_{i}}{\partial x}\right)+\frac{\partial}{\partial y}\left(K_{x y} \frac{\partial C_{i}}{\partial y}\right)+\frac{\partial}{\partial z}\left(K_{z} \frac{\partial C_{i}}{\partial z}\right)-\sigma_{i} C_{i}+S_{i}+R_{i}, i=1, \ldots, n_{S} . \\
-L x / 2 \leq x \leq L x / 2,-L y / 2 \leq y \leq L y / 2, h(x, y) \leq z \leq H, 0 \leq t \leq T,
\end{gathered}
$$

where $C_{i}$ is the concentration of the $i$-th component of the pollutant, $U, V$ are the components of the vector of horizontal wind speed, $\mathrm{W}$ is the vertical wind velocity, $\mathrm{S}_{\mathrm{i}}$ is the source term representing emissions of pollutant components in the atmosphere due to the elevated point and the linear land-based sources, $\mathrm{R}_{i}$ describes the formation and transformation of substance due to the chemical and photochemical reactions involving pollutant components, $\sigma_{\mathrm{i}}$ is the rate of wet deposition of pollutants, $\mathrm{n}_{\mathrm{s}}$ is the number of chemical components of pollutant whose concentrations were modelled, $\mathrm{x}, \mathrm{y}$ are horizontal coordinates, the Ox axis is directed eastwards, the Oy axis is directed northwards, $\mathrm{z}$ is the vertical coordinate, $\mathrm{t}$ is time, and $\mathrm{T}$ is the modeling period. The computational domain represents a parallelepiped, $\mathrm{Lx}$, Ly are the horizontal dimensions of the domain, $\mathrm{H}$ is the height of the computational domain, and $h(x, y)$ is the terrain height above sea level.

Background gas-phase and aerosol concentrations are used as initial conditions, and a 24-h spin-up period was used before the actual numerical prediction. The upper boundary of the computational 
domain is set at $1-\mathrm{km}$ height and horizontal dimensions are $\mathrm{Lx}=\mathrm{Ly}=50 \mathrm{~km}$. Simple gradient conditions for concentrations are applied at the upper boundary. The so-called "radiation" type computational conditions $[9,10]$ that ensure the computational stability of calculations are used at the lateral boundaries. At the lower boundary of the computational domain, which is a rectangle of $50 \times$ $50 \mathrm{~km}^{2}$ with the city of Tomsk in the centre (Figure 1), dry deposition of atmospheric pollutants due to the resistance of the viscous sublayer, aerodynamic resistance, and resistance due to the distribution of vegetation are considered [11].

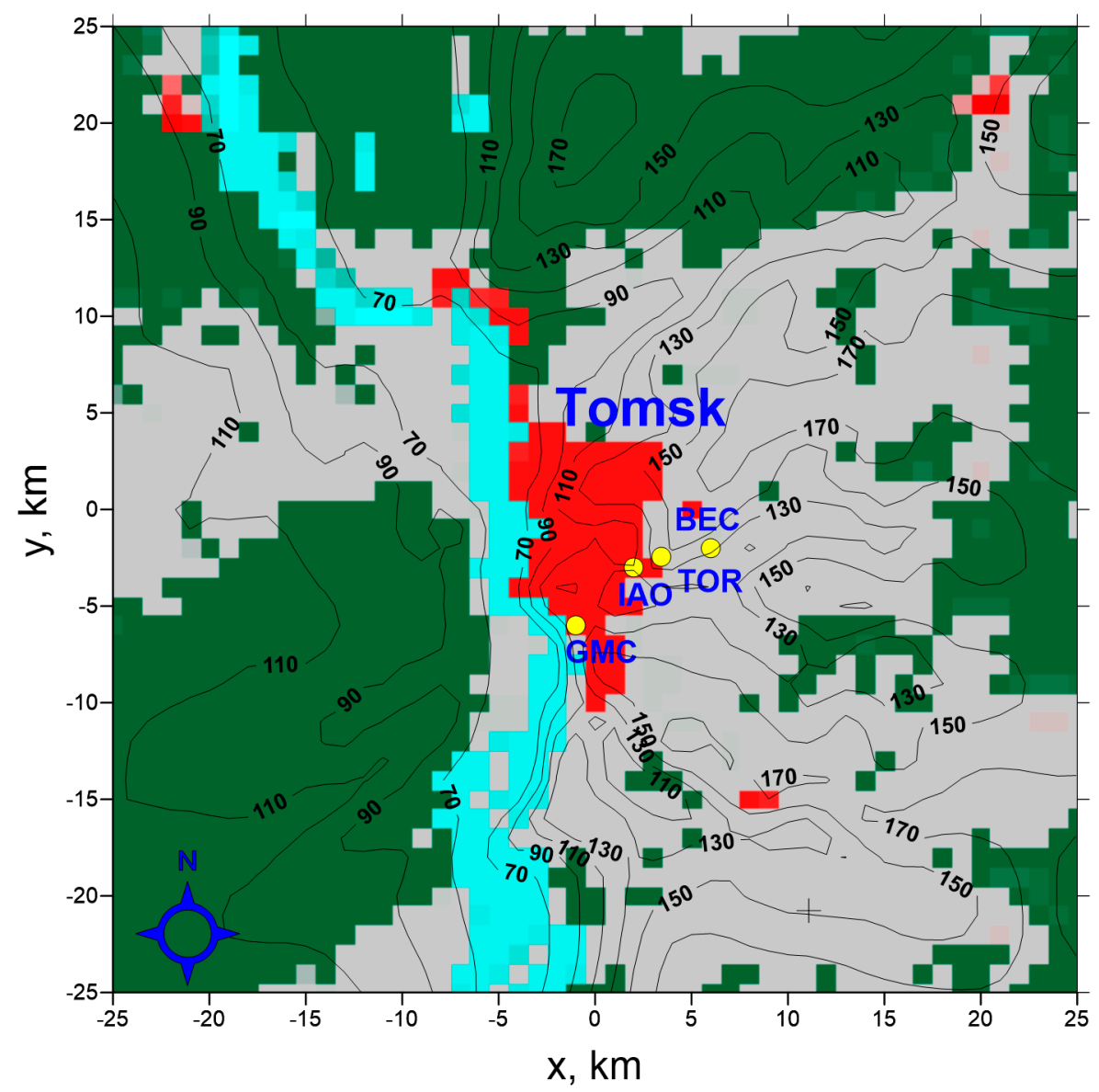

Figure 1. Terrain of the computational domain with the location of the observation sites (yellow dots), water (blue), shrub or grassland (light gray), forest (green), and urbanized areas (red). Contour lines represent terrain height (in meters) above sea level. The extent of computational domain is given in $\mathrm{km}$.

The emissions of primary air pollutants $\left(\mathrm{S}_{\mathrm{i}}\right.$ in $\left.(1)\right)$ are road transport (ground-based sources) and exhaust stacks of industrial enterprises and residential heating facilities (elevated sources) that warm city residents in the cold season.

Such parameters as speed, temperature, flow rate, and elemental composition of the emission are taken into account when setting pollutant entry intensity. These parameters had constant values during a day for the elevated sources. For the ground-based linear sources, the normalized emission rate was set, according to the following law.

$$
\left.i_{\text {Vehicle }}\left(t_{h}\right)\right)=\left\{\begin{array}{l}
0.05+0.95 \sin \left(\pi\left(t_{h}-6\right) / 18\right), t_{h} \in[6.24] \\
0.05, t_{h} \notin[6.24]
\end{array}\right.
$$

here $t_{h}$ is the local time in hours.

The total amount of pollutants emitted into the city's atmosphere per day from ground-based and elevated sources corresponds to the average daily volume of harmful substances in 2018 [12]. 
To describe chemical and photochemical reactions $\left(R_{i}\right.$ in (1)), we propose applying a kinetic scheme derived from a combination of two well-tested reduced chemical reaction mechanisms $[13,14]$. The modification mainly related to the semi-empirical mechanism of the General Reaction Set (GRS) [13], which compactly describes secondary air pollutant formation $\left(\mathrm{O}_{3}, \mathrm{PM}_{2.5}, \mathrm{PM}_{10}\right.$, Radical Pool (RP), $\mathrm{H}_{2} \mathrm{O}_{2}$, etc.). One-stage reaction of ozone formation from Reference [13]:

$$
\mathrm{NO}_{2}+\mathrm{hv} \rightarrow \mathrm{NO}+\mathrm{O}_{3}
$$

was replaced by five reactions from Reference [14] with intermediate states of atomic oxygen.

$$
\begin{gathered}
\mathrm{NO}_{2}+\mathrm{hv} \rightarrow \mathrm{O}\left({ }^{3} \mathrm{P}\right)+\mathrm{NO} \\
\mathrm{O}_{3}+\mathrm{hv} \rightarrow \mathrm{O}\left({ }^{1} \mathrm{D}\right)+\mathrm{O}_{2} \\
\mathrm{O}\left({ }^{3} \mathrm{P}\right)+\mathrm{O}_{2} \rightarrow \mathrm{O}_{3} \\
\mathrm{O}\left({ }^{1} \mathrm{D}\right)+\mathrm{N}_{2} \rightarrow \mathrm{O}\left({ }^{3} \mathrm{P}\right)+\mathrm{N}_{2} \\
\mathrm{O}\left({ }^{1} \mathrm{D}\right)+\mathrm{O}_{2} \rightarrow \mathrm{O}\left({ }^{3} \mathrm{P}\right)+\mathrm{O}_{2}
\end{gathered}
$$

This modification of the GRS mechanism [13] will allow us to describe the process of ground-level ozone formation in more detail and to model additional, fairly compact generation of particles of $2.5 \mu \mathrm{m}$ and $10 \mu \mathrm{m}$ in the city atmosphere. Table 1 shows the final chemical reactions of the modified GRS chemical mechanism. Here, Rsmog is the reacting part of smog emitted by transport and point sources, $R P$ is organic radicals, $O\left({ }^{1} \mathrm{D}\right)$ is the excited state of atomic oxygen, and $\mathrm{O}\left({ }^{3} \mathrm{P}\right)$ is the ground state of atomic oxygen. Stable non-gaseous compounds of organic carbon (SNGOC), nitrogen (SNGN), and sulfur (SNGS) are the components of air-born aerosol particles [13].

Table 1. Chemical reactions of the modified GRS kinetic mechanism.

\begin{tabular}{ccc}
\hline Reactions & Reaction Rate & Source \\
\hline Rsmog $+\mathrm{hv} \rightarrow \mathrm{RP}+\mathrm{Rsmog}+\mathrm{nSNGOC}$ & $\mathrm{r}_{1}=\mathrm{k}_{1} \mathrm{C}_{\mathrm{smog}}$ & {$[13]$} \\
$\mathrm{RP}+\mathrm{NO} \rightarrow \mathrm{NO}_{2}$ & $\mathrm{r}_{2}=\mathrm{k}_{2} \mathrm{C}_{\mathrm{RP}} \mathrm{C}_{\mathrm{NO}}$ & {$[13]$} \\
$\mathrm{RP}+\mathrm{RP} \rightarrow \mathrm{RP}+\mathrm{H}_{2} \mathrm{O}_{2}$ & $\mathrm{r}_{3}=\mathrm{k}_{3} \mathrm{C}_{\mathrm{RP}} \mathrm{C}_{\mathrm{RP}}$ & {$[13]$} \\
$\mathrm{RP}+\mathrm{NO}_{2} \rightarrow \mathrm{SGN}$ & $\mathrm{r}_{4}=\mathrm{k}_{4} \mathrm{C}_{\mathrm{RP}} \mathrm{C}_{\mathrm{NO} 2}$ & {$[13]$} \\
$\mathrm{RP}+\mathrm{NO}_{2} \rightarrow \mathrm{SNGN}$ & $\mathrm{r}_{5}=\mathrm{k}_{5} \mathrm{C}_{\mathrm{RP}} \mathrm{C}_{\mathrm{NO} 2}$ & {$[13]$} \\
$\mathrm{RP}+\mathrm{SO}_{2} \rightarrow \mathrm{SNGS}$ & $\mathrm{r}_{6}=\mathrm{k}_{6} \mathrm{C}_{\mathrm{RP}} \mathrm{C}_{\mathrm{SO} 2}$ & {$[13]$} \\
$\mathrm{H}_{2} \mathrm{O}_{2}+\mathrm{SO}_{2} \rightarrow \mathrm{SNGS}$ & $\mathrm{r}_{7}=\mathrm{k}_{7} \mathrm{C}_{\mathrm{H} 222} \mathrm{C}_{\mathrm{SO} 2}$ & {$[13]$} \\
$\mathrm{O}_{3}+\mathrm{SO}_{2} \rightarrow \mathrm{SNGS}$ & $\mathrm{r}_{8}=\mathrm{k}_{8} \mathrm{C}_{\mathrm{O}} \mathrm{C}_{\mathrm{SO} 2}$ & {$[13]$} \\
$\mathrm{NO}_{2}+\mathrm{hv} \rightarrow \mathrm{O}\left({ }^{3} \mathrm{P}\right)+\mathrm{NO}$ & $\mathrm{r}_{9}=\mathrm{k}_{9} \mathrm{C}_{\mathrm{NO} 2}$ & {$[14]$} \\
$\mathrm{O}_{3}+\mathrm{hv} \rightarrow \mathrm{O}\left({ }^{1} \mathrm{D}\right)+\mathrm{O}_{2}$ & $\mathrm{r}_{10}=\mathrm{k}_{10} \mathrm{C}_{\mathrm{O} 3}$ & {$[14]$} \\
$\mathrm{O}\left({ }^{3} \mathrm{P}\right)+\mathrm{O}_{2} \rightarrow \mathrm{O} \mathrm{O}_{3}$ & $\mathrm{r}_{11}=\mathrm{k}_{11} \mathrm{C}_{\mathrm{O}(3 \mathrm{P} P} \mathrm{C}_{\mathrm{O} 2}$ & {$[14]$} \\
$\mathrm{O}\left({ }^{1} \mathrm{D}\right)+\mathrm{N}_{2} \rightarrow \mathrm{O}\left({ }^{3} \mathrm{P}\right)+\mathrm{N}_{2}$ & $\mathrm{r}_{12}=\mathrm{k}_{12} \mathrm{C}_{\mathrm{O}}(1 \mathrm{D}) \mathrm{C}_{\mathrm{N} 2}$ & {$[14]$} \\
$\mathrm{O}\left({ }^{1} \mathrm{D}\right)+\mathrm{O}_{2} \rightarrow \mathrm{O}\left({ }^{3} \mathrm{P}\right)+\mathrm{O}_{2}$ & $\mathrm{r}_{13}=\mathrm{k}_{13} \mathrm{C}_{\mathrm{O}}(1 \mathrm{D}) \mathrm{C}_{\mathrm{O} 2}$ & {$[14]$} \\
$\mathrm{O}_{3}+\mathrm{NO} \rightarrow \mathrm{NO}_{2}+\mathrm{O}_{2}$ & $\mathrm{r}_{14}=\mathrm{k}_{14} \mathrm{C}_{\mathrm{O} 3} \mathrm{C}_{\mathrm{NO}}$ & {$[14]$} \\
\hline
\end{tabular}

A non-hydrostatic mesoscale meteorological model of Tomsk State University, TSUNM3 [15], was used to calculate three-dimensional wind speed fields and turbulent diffusion coefficients for Equation (1). After computing meteorological parameters for the area of interest, the distribution of pollutant concentration was calculated with the CTM described above. The TSUNM3 mesoscale model predicts wind speed components and temperature and humidity characteristics in the atmospheric boundary layer at 50 vertical levels (up to $10 \mathrm{~km}$ ) for a territory of $150 \times 150 \mathrm{~km}^{2}$ and the nested are of $50 \times 50 \mathrm{~km}^{2}$ (grid step of $1 \mathrm{~km}$ with Tomsk in the center).

The TSUNM3 model takes into account the following atmospheric processes: 
- turbulent mixing in the atmospheric boundary layer, whose nature is significantly affected by changes in the temperature of the underlying terrain,

- heat propagation by short-wave and long-wave radiation in the considered layer of the atmosphere, taking into account clear-sky scattering and attenuation, water vapor absorption, absorption, and reflection by clouds,

- formation of raindrops, clouds, snow, ice particles, and graupel in the atmosphere from the atmospheric moisture,

- turbulent exchange of momentum, heat, and moisture with the underlying terrain,

- $\quad$ heating of the underlying terrain by penetrating solar short-wave radiation and its cooling by long-wave radiation that becomes especially apparent in the dark.

The key features of TSUNM3 model [7,15]:

- non-hydrostatic quasi-compressible approximation for the continuity equation,

- a terrain following vertical sigma coordinate system with a variable resolution [16],

- lateral boundary conditions of the "radiation" type [9,10] (for horizontal velocity, temperature, and humidity components), which take into account the spatial and temporal trends of dependent variables generated by the larger scale model (the Semi Lagrangian-Absolute Vorticity (SL-AV) operational global model of Hydrometeorological Center of the Russian Federation [17]),

- a predictive model for soil temperature based on the heat equation and a diagnostic ratio for moisture of the soil surface layer,

- surface heat flows, which are calculated on the basis of the similarity theory of Monin-Obukhov,

- short-wave and long-wave radiation, which takes into account the effects of the cloud layer [18,19],

- the Weather Research \& Forecasting (WRF) single-moment 6-class scheme (WSM6) [20], which considers six classes of atmospheric moisture states (water vapor, cloudy moisture, rain moisture, ice particles, snow, graupel, hail),

- the turbulent structure of the atmospheric boundary layer, which is simulated on the basis of the transport equation for turbulence energy and algebraic relations for the length scale of turbulence and turbulent diffusion [21,22],

- there is a parallel version of the mesoscale model developed using the standard of parallel programming for systems with distributed memory—the Message Passing Interface.

The TSUNM3 model is initialized by boundary conditions from the operational global numerical weather prediction model SL-AV [17].

Observation data of near ground meteorological parameters and concentrations of major air pollutants $\left(\mathrm{CO}, \mathrm{SO}_{2}, \mathrm{O}_{3}\right)$ as well as calculations by the mesoscale model of air quality CAMx (Comprehensive Air Quality Model with eXtension [23]) were used to verify the reliability of the results obtained from the developed photochemical mesoscale model with a modified kinetic GRS mechanism. The measurements were made by the Tropospheric Ozone Research station (TOR), the IAO observation site (IAO), and the Basic Experimental Complex (BEC) of the JUC "Atmosphere" of the of V.E. Zuev Institute of Atmospheric Optics. Weather observations at the Tomsk weather station (GMC) were also used. Figure 1 shows the location of these observation sites.

IAO station instruments are located on the roof of the laboratory building (Eastern outskirts of Tomsk). The MTP-5 temperature profiler and the Meteo- 2 ultrasonic weather station were used to measure weather parameters. The height of these instruments above the roof level is $5 \mathrm{~m}(17 \mathrm{~m}$ above the level of the underlying surface). MTP- 5 measures air temperature from its location level to $1000 \mathrm{~m}$ with $50 \mathrm{~m}$ height increments and $5 \mathrm{~min}$ time increments. Meteo- 2 measures air temperature and relative humidity, atmospheric pressure, and wind vector components at the point of its location with a frequency of 10 times per second.

BEC is located in the short-distance suburbs of Tomsk (to the East-Northeast). There is a natural landscape (a large clearing surrounded by woodlands) with several one-story buildings. The Meteo-2 
ultrasonic meteorological station (BEC), located at $5 \mathrm{~m}$ height above the level of the underlying surface, was used to measure weather parameters. In addition, automatic systems were installed to measure concentrations of trace gases and aerosols in the surface layer of the atmosphere.

The TOR station is an automatic station located in the building of the IAO high altitude station in the North-Eastern suburbs of Tomsk. There are no industrial facilities or highways near the station, which reduces the impact of local gas and aerosol sources. Since the station is located in the boreal forest area, there are small woodlands of deciduous and coniferous species around it. During air movement with the Western wind component (i.e., W, S-W, N-W wind), the station is influenced by the air having passed through the territory of the city of Tomsk and polluted with industrial and motor transport emissions. In other cases, air comes from the areas with high proportion of woodlands and no industrial enterprises. The TOR station is designed to monitor $\mathrm{CO}, \mathrm{CO}_{2}, \mathrm{NO}, \mathrm{NO}_{2}, \mathrm{SO}_{2}, \mathrm{O}_{3}$, aerosol particle size distribution, and meteorological values. GMC is located in the Southern part of the city and performs standard weather observations.

CAMx model runs were performed with meteorological fields calculated with Weather Research \& Forecasting modeling system for the computational domain of $50 \times 50 \mathrm{~km}^{2}$ with Tomsk in its center (Figure 1). The distribution of linear and elevated sources coincided with that described in Section 2. Chemistry mechanism Carbon Bond 6r2 gas-phase chemistry and CF coarse and fine aerosol particles mechanisms were selected in CAMx simulations.

WRF (version 3.7.1) model [24] was run with the following configuration:

- $\quad$ three nested domains of $450 \times 450,150 \times 150,50 \times 50 \mathrm{~km}^{2}$ with horizontal grid steps of 9, 3, and $1 \mathrm{~km}$, respectively,

- microphysics of moisture (mp_physics): WSM6 scheme for all three areas,

- long-wave radiation (ra_lw_physics): Rapid Radiation Transfer Model,

- $\quad$ short-wave radiation (ra_sw_physics): Dudhia scheme,

- $\quad$ surface layer (sf_sfclay_physics): a model based on the Monin-Obukhov similarity theory developed for the MM5 model,

- the Earth's surface (sf_surface_physics) is represented with the Noah Land Surface Model,

- $\quad$ planetary boundary layer (bl_pbl_physics): the Yonsei University scheme,

- cloud cover (cu_physics): the Kain-Fritsch scheme for the large domain, cloud cover was calculated explicitly for the second and third nested domains.

The comparison of observed and simulated meteorological parameters and concentration of pollutants are presented below. Figure 2 shows changes in temperature and humidity, wind speed, and direction for 28 July 2013. According to the observations of the Tomsk weather station (GMC point in Figure 1), that day was characterized by calm winds with North, North-East directions, scattered clouds, moderate humidity, and air temperature that varied during the day from 13 to 26 degrees. The comparison of the calculated and measured values of meteorological parameters shows that the TSUNM3 model predicts weather changes effectively during the selected day. 

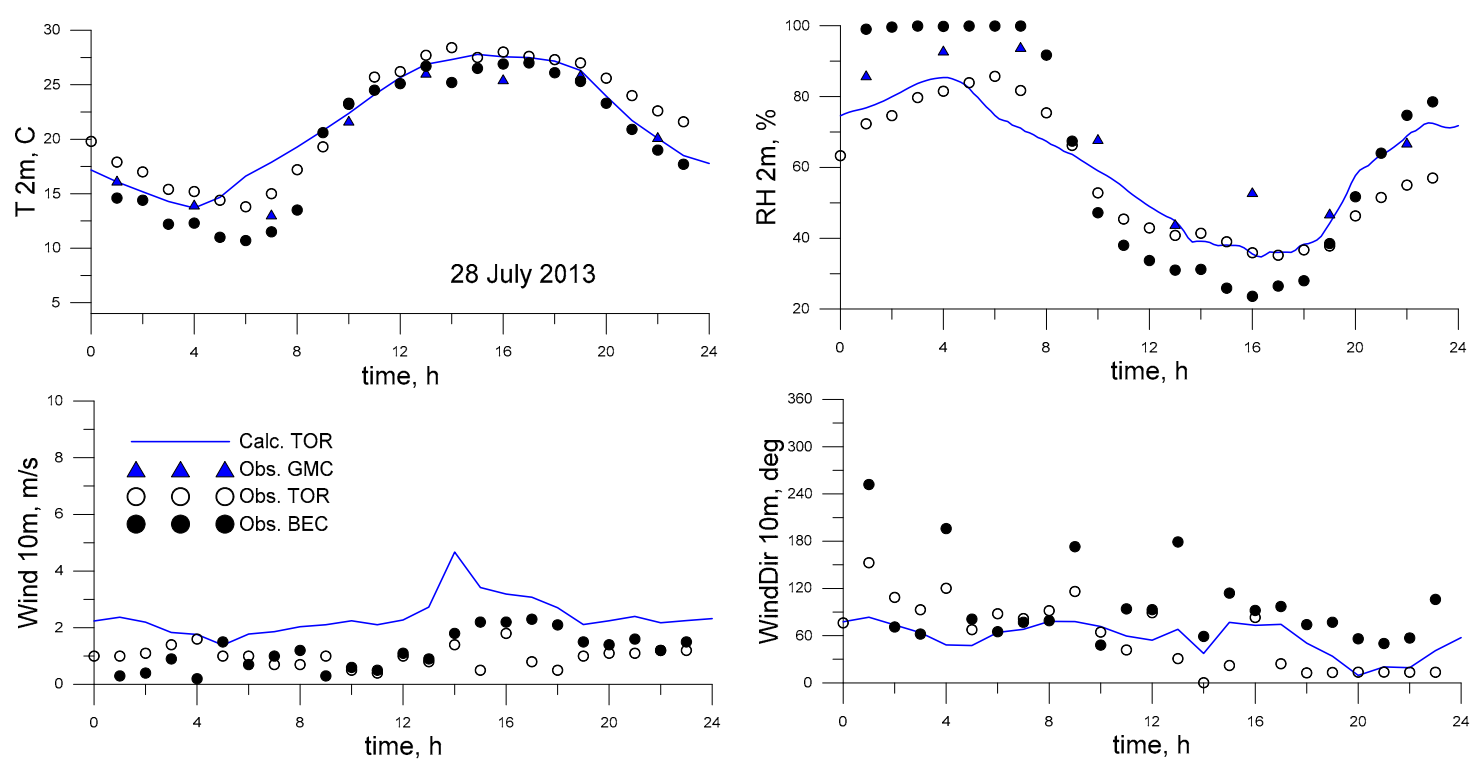

Figure 2. Calculated and measured near ground meteorological values at the observation sites. The blue lines are the results of numerical prediction at the TOR station and symbols are observation data (open circles-TOR, closed circles-BEC, triangles-GMC).

Figure 3 shows changes in the concentrations of carbon monoxide, sulfur dioxide, ozone, and aerosol particles calculated by the selected atmospheric air quality models $[8,23]$ and measured at the TOR and BEC sites. Table 2 shows the non-zero background concentrations of the calculated pollutants.
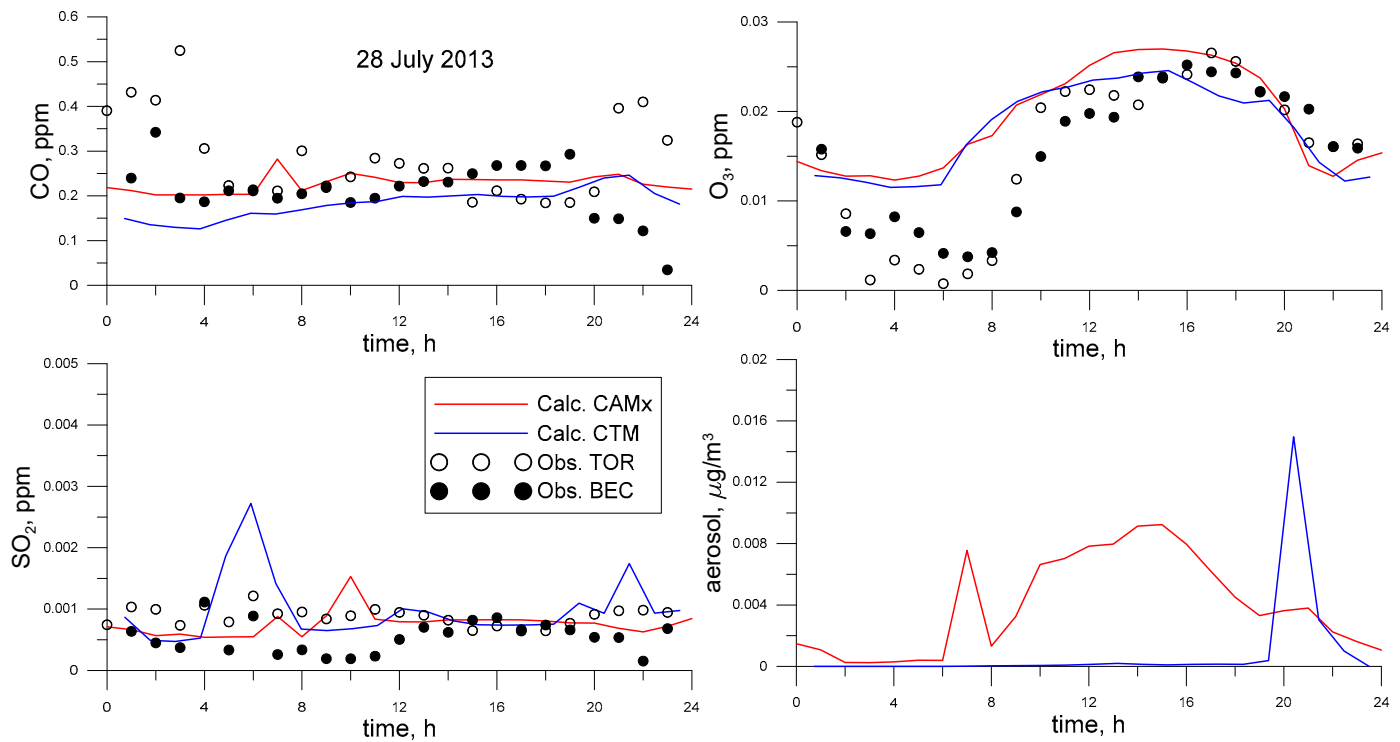

Figure 3. The simulation results at the TOR station carried out by the developed CTM (blue lines) and CAMx (red lines) models. The observations of atmospheric composition are given at the TOR (open circles) and BEC (closed circles) stations.

Table 2. Background concentrations.

\begin{tabular}{ccccc}
\hline $\mathrm{CO}, \mathrm{ppb}$ & $\mathrm{SO}_{2}, \mathbf{p p b}$ & $\mathrm{NO}_{2}, \mathbf{p p b}$ & $\mathbf{O}_{3}, \mathbf{p p b}$ & $\mathrm{NO}, \mathbf{p p b}$ \\
\hline 200.0 & 0.7 & 20.0 & 20.0 & 0.1 \\
\hline
\end{tabular}


Figure 3 shows that both models predicted a slight change in the concentration of $\mathrm{CO}$ at the TOR observation site, even though the measured values coincided completely with the calculations during the day and showed a deterioration in air quality during the night, morning, and evening hours (note a significant difference in the measured values of $\mathrm{CO}$ concentration at BEC and TOR during these hours). Both models predicted similar values for ground-level ozone concentrations that were satisfactorily consistent with the observations after 12 p.m. However, measurements at weather stations showed a significant decrease in the concentration of ozone in the first half of the day. Both models also showed good agreement with the results of measurements of sulfur dioxide concentrations. The TSU photochemical mesoscale model calculated a small increase in $\mathrm{SO}_{2}$ concentration at 5 and 20 o'clock.

Statistical methods were used to evaluate agreement between computations and observations based on the presented models. The metrics frequently used to assess the effectiveness of multi-scale meteorological models [25] can serve as such a method. Here, we consider the normalized root-mean-square error (NMSE), the fractional bias (FB), and the fraction of predictions within a factor of two of observations (FAC2) that satisfies the ratio $0.5 \leq \mathrm{P}_{\mathrm{i}} / \mathrm{O}_{\mathrm{i}} \leq 2.0$, where $\mathrm{P}_{\mathrm{i}}$ is the value calculated based on the model, and $\mathrm{O}_{\mathrm{i}}$ is the measured value. For the computational model to be of satisfactory quality, the statistical parameters presented above must take on the following values [25]: NMSE $<4,|\mathrm{FB}|<0.3$, FAC2 $>0.5$.

Table 3 shows the calculated metrics for model validation. We consider the computation and observation results for the position of the TOR station as of 28 July 2013. Based on the presented results, one can notice that the mesoscale meteorological model predicts the observed values of temperature and humidity at $2 \mathrm{~m}$ height and the wind direction at $10 \mathrm{~m}$ height quite well for the time period under consideration. The agreement of $10 \mathrm{~m}$ wind speed was somewhat worse. The computation results overestimate the observed values. If we apply the same values to analyze agreement between the calculated and measured values of concentrations (Figure 3), one can see a fairly good prediction of changes in ozone concentration and slightly worse prediction of sulfur dioxide and carbon monoxide concentrations in the area of the TOR station.

Table 3. Validation metrics at the TOR station for 28 July 2013.

\begin{tabular}{cccccccc}
\hline Metrics & T2 & RH2 & Wind10 & WDir10 & CO & SO $_{2}$ & $\mathbf{O}_{3}$ \\
\hline NMSE & 0.01 & 0.02 & 1.03 & 0.29 & 0.42 & 0.35 & 0.14 \\
FB & 0.03 & -0.06 & -0.82 & 0.04 & 0.43 & -0.15 & -0.17 \\
FAC2 & 1.00 & 1.00 & 0.33 & 0.67 & 0.79 & 0.83 & 0.75 \\
\hline
\end{tabular}

In general, analyzing the results from Figures 2 and 3 and Table 3, we can conclude that, for the investigated period (28 July 2013), calculations based on air quality models are in acceptable agreement with each other and with the experiments performed with the JUC "Atmosphere" instruments.

\section{Results and Discussion}

Several historical dates were selected in 2018 to study the influence of cold Siberian winter weather on the quality of atmospheric air over the city. These dates are characterized by calm wind, low temperatures with their large diurnal amplitude variations under mostly cloud-free conditions (Table 4).

Information from Reference [26] was used to model the value of anthropogenic heat flow from the surface of the urban area ("urbanized areas" land use category). The research [26] recommends the most universal profile of changes in the normalized value of anthropogenic heat flow during the day, which is also used in the WRF [24]. According to the recommendation [26], $25 \mathrm{~W} / \mathrm{m}^{2}$ for the warm period of the year and $90 \mathrm{~W} / \mathrm{m}^{2}$ for the cold period were chosen as the maximum anthropogenic heat flux values for Tomsk.

The numerical weather prediction by the TSUNM3 model for the selected dates (Table 4) showed several common features of the studied meteorological processes, which will be demonstrated for two 
selected dates. Our simulation results were compared with the observation data from the IAO and BEC sites (Figure 1).

Table 4. The investigated time periods and their meteorological parameters for Tomsk.

\begin{tabular}{ccccc}
\hline Date & Wind, $\mathbf{m} / \mathbf{s}$ & Direction, deg & $\boldsymbol{\Delta} \mathbf{T},{ }^{\circ} \mathbf{C}$ & Humidity, $\%$ \\
\hline 3 January 2018 & $1-2$ & about 90 & $(-26,-16)$ & $\sim 90$ \\
1 February 2018 & $1-2$ & about 90 & $(-25,-10)$ & $\sim 80$ \\
6 February 2018 & $1-2$ & $140-180$ & $(-30,-12)$ & $\sim 80$ \\
19 November 2018 & $1-2$ & $140-180$ & $(-28,-16)$ & $\sim 80$ \\
11 December 2018 & 1 & about 100 & $(-26,-12)$ & $\sim 80$ \\
28 December 2018 & 1 & $100-120$ & $(-35,-22)$ & $70-80$ \\
\hline
\end{tabular}

Figure 4 shows experimental and numerical calculation results of $10 \mathrm{~m}$ wind speed, its direction, and $2 \mathrm{~m}$ temperature for $24 \mathrm{~h}$ of 1 February 2018 and 19 November 2018. The figure shows that both calculations and observations (for most of the day) show a weak easterly, south-easterly wind slightly changing its speed and its direction during the day due to the prevailing calm, cloudless, dry, anticyclonic weather.
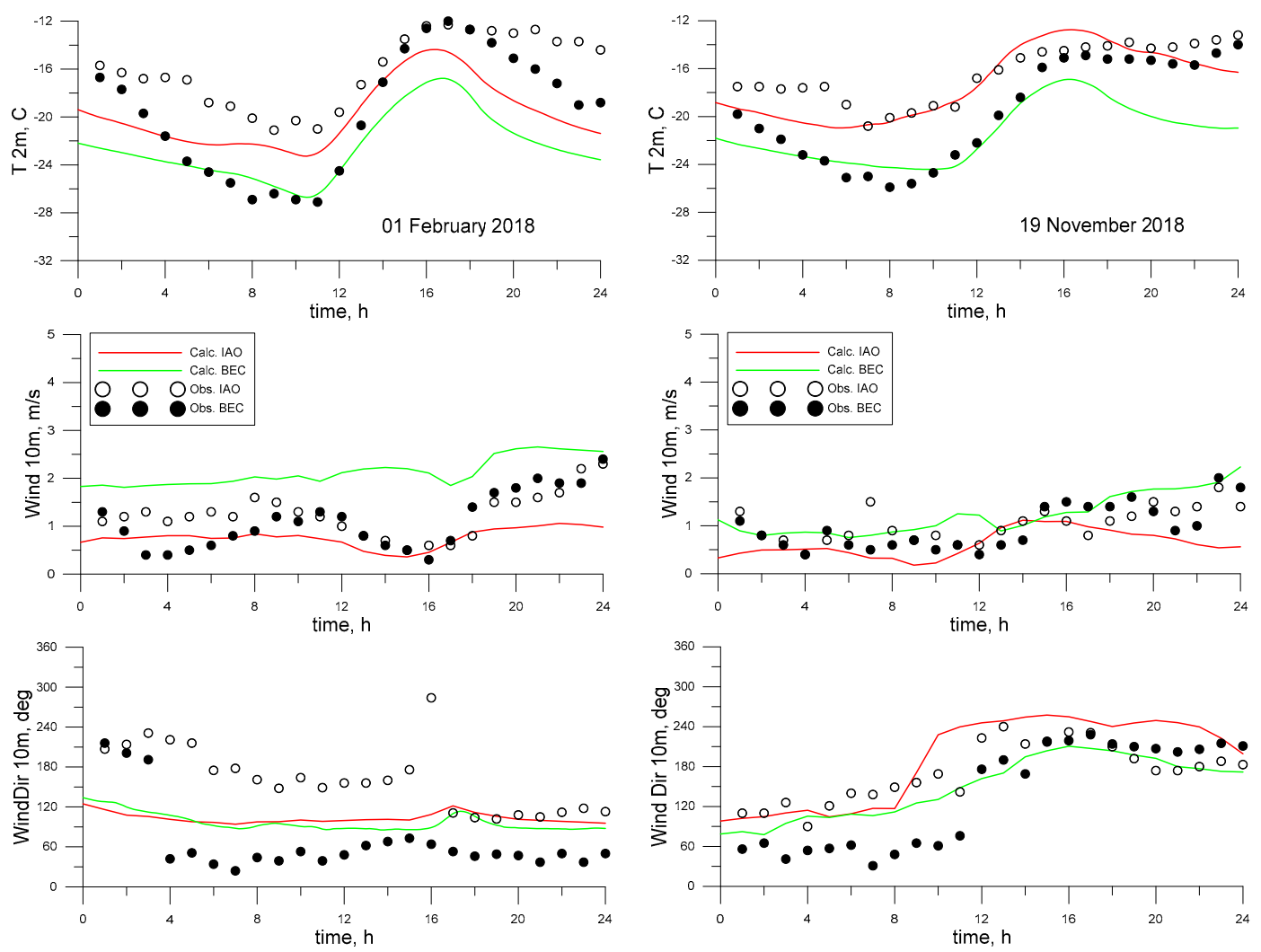

Figure 4. Numerical and experimental values of $2 \mathrm{~m}$ temperature, $10 \mathrm{~m}$ wind speed, and direction for 1 February 2018 (left) and 19 November 2018 (right). Lines indicate the results of numerical predictions (red-IAO station, green-BEC station), and circles indicate observation data (open circles-IAO, closed circles-BEC).

We should note that wind speed and direction also slightly change for the points with the Meteo-2 ultrasonic meteorological stations located inside and outside the city. As it follows from the results of calculations and measurements, the lowest values of air temperature near the surface are observed at night. This is due to the strong cooling of the surface covered with snow during calm winds and clear sky weather conditions. The near ground air temperature values are lower outside the city than in the 
city. The temperature difference reaches several degrees, according to the calculations and observations. The air temperature increase near the earth's surface during the day is associated with solar radiation. The values of air temperatures in the city and outside the city converge with the highest altitude of the sun.

Figure 5 proves the above said and presents the isolines of $2 \mathrm{~m}$ air temperature and $10 \mathrm{~m}$ wind field calculated using the TSUNM3 model for 4:00 a.m., 1 February 2018 and 19 November 2018. The figure shows that the "heat island" is much stronger at night, although a significant increase in temperature does not have any significant effect on the $10 \mathrm{~m}$ wind speed.
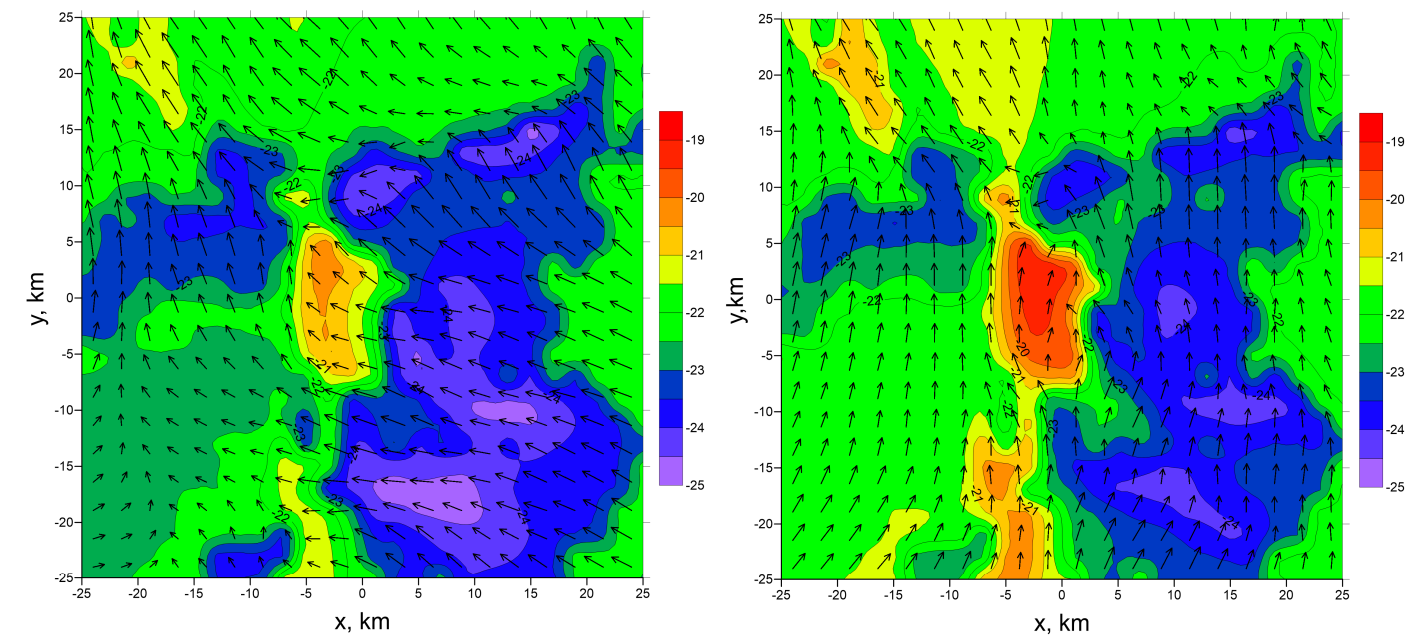

Figure 5. The urban heat island (in the center of the domain) calculated by TSUNM3 on 1 February 2018 (left) and 19 November 2018 (right), 4 a.m. local time. The contour maps indicate $2 \mathrm{~m}$ temperature (in ${ }^{\circ} \mathrm{C}$ ) and the vector field is $10 \mathrm{~m}$ wind speed. The distribution of land use categories is shown in Figure 1. The extent of the computational domain is given in $\mathrm{km}$.

Figure 6 shows vertical air temperature profiles at various time points, calculated by TSUNM3 and observed by MTP- 5 temperature profiler at the IAO station. As seen from simulation results, a stable stratification below $500 \mathrm{~m}$ was observed over the city at night. More intense inversion is observed in the lowest layer (20:00-08:00). A small layer of unstable stratification is formed in the atmosphere up to a height of about $100 \mathrm{~m}$ (16:00, local time) in the daytime as a result of solar heating of the underlying terrain. Such changes in stratification on diurnal cycle indicate the probability of accumulation of pollutants emitted into the atmosphere near the surface during the night, morning, and evening hours.

The photochemical mesoscale model described in Section 2 was applied to study the influence of meteorological conditions during the day on the atmospheric air quality in the city. The intensity of the elevated point and ground-based linear sources was set in the way described above in Sections 2 and 3. Background values of the pollutants were assessed based on the observation results of near surface air composition at the TOR station of IAO SB RAS [27].

To assess an air quality, the Air Pollution Index (API) was used. The API values are calculated based on the predicted concentrations of $\mathrm{CO}, \mathrm{SO}_{2}, \mathrm{NO}_{2}, \mathrm{NO}$, and $\mathrm{O}_{3}$ with the following equation.

$$
\mathrm{API}=\sum_{\mathrm{i}=1}^{\mathrm{n}}\left(\frac{\mathrm{C}_{\mathrm{i}}}{\mathrm{C}_{\mathrm{i} \infty}}\right)^{a_{\mathrm{i}}}
$$

where $C_{i}$ is the concentration of the $\mathrm{i}$-th substance, $\mathrm{mg} / \mathrm{m}^{3}$, values of $C_{i \infty}, \mathrm{mg} / \mathrm{m}^{3}$, and the dimensionless constants $a_{i}$ are presented in Table 5 . 


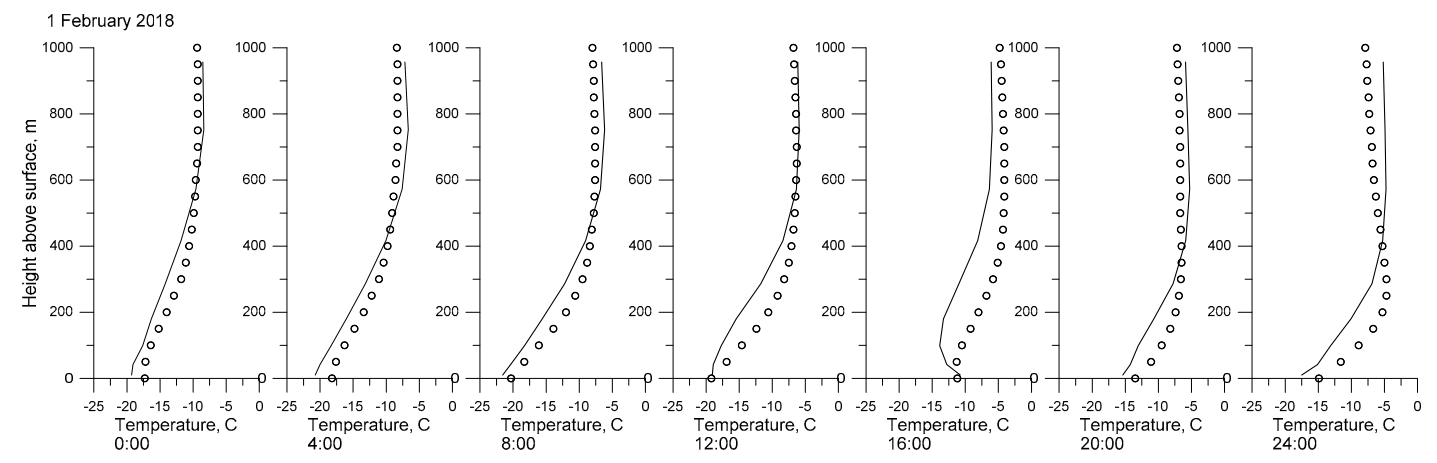

(a)

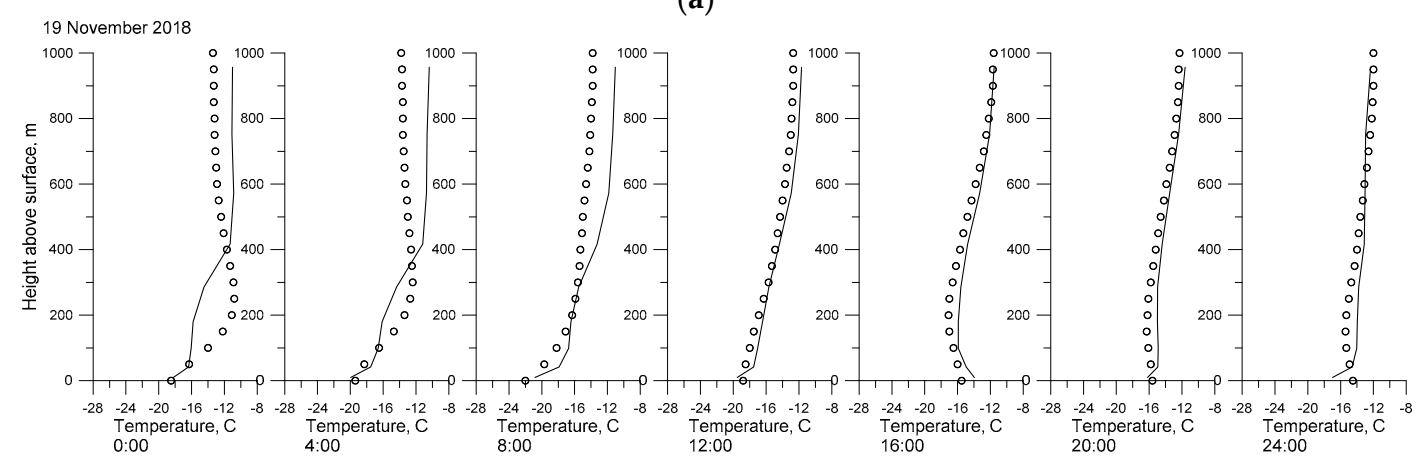

(b)

Figure 6. Observations and modelling results of vertical temperature profiles for various time points on 1 February 2018 (a) and 19 November 2018 (b) at the IAO station.

Table 5. The constants for calculating the Air Pollution Index (3).

\begin{tabular}{cccccc}
\hline Constants in (3) & $\mathbf{C O}$ & $\mathbf{S O}_{2}$ & $\mathbf{N O}_{2}$ & $\mathbf{N O}$ & $\mathbf{O}_{3}$ \\
\hline $\mathrm{C}_{\mathrm{i} \infty}$ & 5.0 & 0.5 & 0.2 & 0.40 & 0.16 \\
$\mathrm{a}_{\mathrm{i}}$ & 0.9 & 1.0 & 1.3 & 1.0 & 1.7 \\
\hline
\end{tabular}

The API calculated with Equation (3) was recommended for the urban air quality assessment by The Federal Service for Hydrometeorology and Environmental Monitoring (Rosgidromet).

Figure 7 shows changes in the maxima of API (APImax) for each hour for selected modeling dates characterized by low temperatures. One can see two time intervals with local maxima of APImax $\left(t_{h}\right)$. The time period from 12 to 16 o'clock of local time corresponds to the highest traffic intensity in accordance with the emission model (2). This leads to an increase in the API for some dates during this period when there is a quiet wind and unstable near ground air stratification close to the neutral. The second local maximum in Figure 7 is observed from 0 to 6 a.m. The intensity of emissions from motor transport during this time is minimal according to model (2). Therefore, the potential air pollution at this time may occur due to the emissions from industrial and heating enterprises when there is a calm wind and significant stable stratification of an atmospheric boundary layer (refer to Figures 4 and 6). 


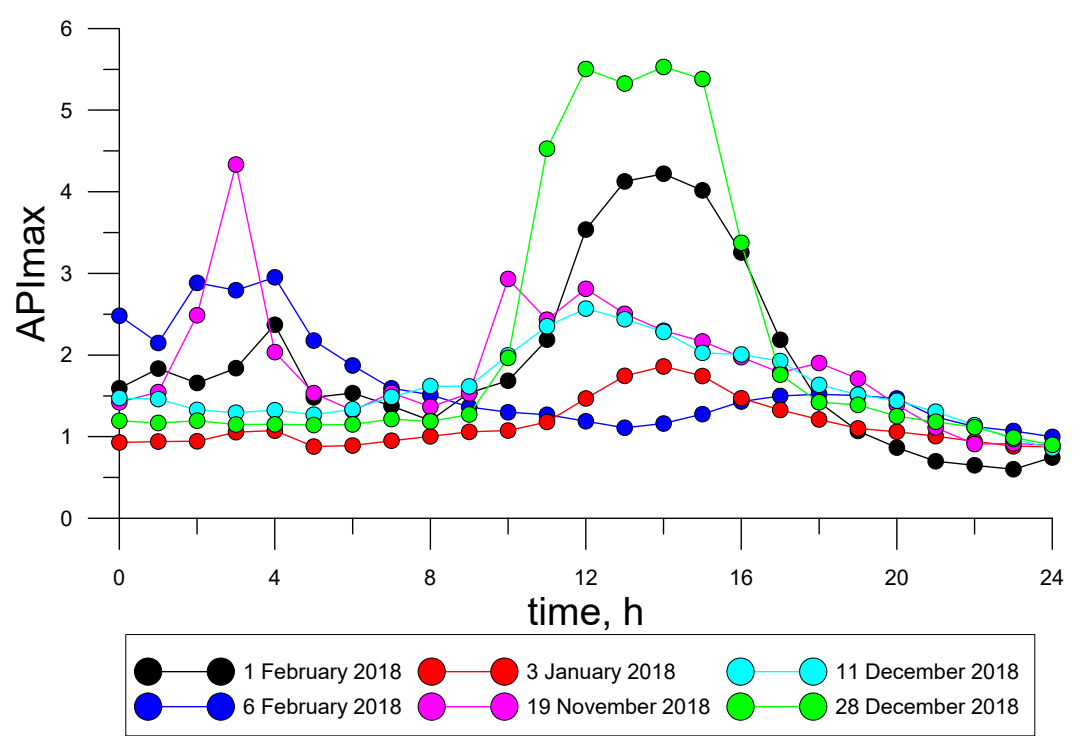

Figure 7. Maximum values of the Air Pollution Index (API) for the selected historical dates for each hour over the territory of $50 \times 50 \mathrm{~km}^{2}$ calculated by the developed CTM model.

\section{Conclusions}

The paper presents the results of calculations of meteorological parameters and parameters that characterize air quality in the city of Tomsk, obtained with the use of mesoscale meteorological and chemical transport models. Changes in the numerically predicted wind velocity fields, temperature, and concentration of major air pollutants were considered in detail for the selected dates when calm, cloudless, dry, and anti-cyclonic weather was observed in Tomsk. The numerical calculation results were compared with the observation data from the JUC "Atmosphere" of IAO SB RAS. The results of modelling, which were also confirmed by observations, have shown that the most unfavorable meteorological conditions for pollutants' accumulation are stable. There is neutral stratification of the near surface air with low ambient air temperatures $\left(-30,-20^{\circ} \mathrm{C}\right)$ and calm winds of various directions.

The new modification of the mesoscale photochemical model was developed. It can model the formation of ground-level ozone and the formation of $2.5-\mu \mathrm{m}$ and $10-\mu \mathrm{m}$ particles in sufficient detail based on reduced kinetic chemical mechanisms. The success of numerical predictions of this model is confirmed by comparison with observational data on pollutant concentrations from the TOR station of IAO SB RAS and calculations performed by the CAMx air quality model.

In addition, the paper shows that the high spatial resolution (1 km grid step) TSUNM3 and CTM model adequately reflect the real state of meteorological parameters and air quality of atmosphere and their changes in time under different weather conditions. This model driven by the global SL-AV model can describe processes with high spatial and temporal resolution, which is very important for achieving high accuracy in calculations. The paper shows the possibility of the model to predict the state of the atmosphere above the city, including the heat island and its characteristics (intensity, horizontal extent, lifetime, differences between urban temperature, suburban temperature, and humidity values, and air circulation).

Author Contributions: A.S. and L.K. conceived of and designed the numerical experiments. A.S. and E.S. performed the numerical experiments. A.S. and L.K. analyzed the data. A.S. and L.K. edited the manuscript. E.S. contributed analysis tools for visualization. All authors have read and agreed to the published version of the manuscript.

Funding: This research was funded by the Russian Science Foundation (project no. 19-71-20042).

Conflicts of Interest: The authors declare no conflict of interest. 


\section{References}

1. Sokhi, R.; Baklanov, A.; Schlünzen, H. Mesoscale Modelling for Meteorological and Air Pollution Applications; Anthem Press: New York, NY, USA, 2018; 260p.

2. Chen, R.; Peng, R.D.; Meng, D.X.; Zhou, Z.; Chen, B.; Kan, H. Seasonal variation in the acute effect of particulate air pollution on mortality in the China Air Pollution and Health Effects Study (CAPES). Sci. Total Environ. 2013, 450-451, 259-265. [CrossRef] [PubMed]

3. Czarnecka, M.; Nidzgorska-Lencewicz, J. Impact of weather conditions on winter and summer air quality. Int. Agrophys. 2011, 25, 7-12.

4. Pyanova, E.A.; Penenko, V.V.; Faleychik, L.M. Numerical study of pollutants dispersion in urban atmosphere in warm and cold seasons (Krasnoyarsk city as an example). Proc. SPIE 2019, 11208, 112088C. [CrossRef]

5. Zyromski, A.; Biniak-pierog, M.; Bursta-Adamiak, E.; Zamiar, Z. Evaluation of relationship between air pollutant concentration and meteorological elements in winter months. J. Water Land Dev. 2014, 22, $25-32$. [CrossRef]

6. He, J.; Lu, S.; Yu, Y.; Gong, S.; Zhao, S.; Zhao, C. Numerical Simulation Study of Winter Pollutant Transport Characteristics over Lanzhou City, Northwest China. Atmosphere 2018, 9, 382. [CrossRef]

7. Starchenko, A.V.; Bart, A.A.; Kizhner, L.I.; Danilkin, E.A. Mesoscale meteorological model TSUNM3 for the study and forecast of meteorological parameters of the atmospheric surface layer over a major population center. Tomsk State Univ. J. Math. Mech. 2020, 66, 35-55. [CrossRef]

8. Bart, A.A.; Starchenko, A.V.; Fazliev, A.Z. Information-computational system for air quality short-range prognosis over territory of Tomsk. Opt. Atmos. Okeana 2012, 25, 594-601.

9. Sommerfield, A. Partial Differential Equations in Physics; Academic Press: New York, NY, USA, 1949; 335p.

10. Carpenter, K. Note on the Paper "Radiation Condition for the Lateral Boundaries of Limited-Area Numerical Models". Q. J. Roy. Meteorol. Soc. 1982, 108, 717-719. [CrossRef]

11. Hosker, R.P.; Lindberg, S.E. Review: Atmospheric deposition and plant assimilation of gases and particles. Atmos. Environ. 1982, 16, 889-910. [CrossRef]

12. Official Website of Tomsk Region Administration. Available online: http://en.tomsk.gov.ru (accessed on 4 September 2020).

13. Hurley, P. TAPM V4. Part 1: Technical Description. In CSIRO Marine and Atmospheric Research Paper No. 25; CSIRO Marine and Atmospheric Research: Aspendale, Australia, 2008; 59p. [CrossRef]

14. Stockwell, W.R.; Goliff, W.S. Comment on «Simulation of a reacting pollutant puff, using an adaptive grid algorithm» by R. K. Srivastava et al. J. Geophys. Res. 2002, 107, 4643-4650. [CrossRef]

15. Starchenko, A.V.; Kuzhevskaya, I.V.; Kizhner, L.I.; Barashkova, N.K.; Volkova, M.A.; Bart, A.A. Evalution of the TSUNM3 high-resolution mesoscale NWP model. Opt. Atmos. Okeana 2019, 32, 57-61. [CrossRef]

16. Gal-Chen, T.; Sommerville, R. On the use of a coordinate transformation for the solution of the Navier-Stokes equations. J. Comput. Phys. 1975, 17, 209-228. [CrossRef]

17. Tolstykh, M.A.; Fadeev, R.Y.; Shashkin, V.V.; Goyman, G.S.; Zaripov, R.B.; Kiktev, D.B.; Makhnorylova, S.V.; Mizyak, V.G.; Rogutov, V.S. Multiscale Global Atmosphere Model SL-AV: The Results of Medium-range Weather Forecasts. Russ. Meteorol. Hydrol. 2018, 43, 773-779. [CrossRef]

18. Avissar, R.; Mahrer, Y. Mapping frost-sensitive areas with a three-dimensional local-scale numerical model. Part I. Physical and numerical aspects. J. Appl. Meteorol. 1988, 27, 400-413. [CrossRef]

19. Stephens, G. Radiation profiles in extended water clouds. Part II: Parameterization schemes. J. Atmos. Sci. 1978, 35, 2123-2132. [CrossRef]

20. Hong, S.-Y.; Lim, J.-O.J. The WRF single-moment 6-class microphysics scheme (WSM6). J. Korean Meteorol. Soc. 2006, 42, 129-151.

21. Yamada, T. Simulation of nocturnal drainage flows by a q2l turbulence model. J. Atmos. Sci. 1983, 40, 91-106. [CrossRef]

22. Belikov, D.A.; Starchenko, A.V. Numerical model of turbulent pollutant transport in the atmospheric boundary layer. Atmos. Ocean. Opt. 2007, 20,607-612.

23. CAMx. Available online: http://www.camx.com (accessed on 4 September 2020).

24. Powers, J.G.; Klemp, J.B.; Skamarock, W.C.; Davis, C.A.; Dudhia, J.; Gill, D.O.; Coen, J.L.; Gochis, D.J.; Ahmadov, R.; Peckham, S.E.; et al. The Weather Research and Forecasting Model: Overview, System Efforts and Future Directions. Bull. Am. Meteor. Soc. 2017, 98, 1717-1737. [CrossRef] 
25. Di Sabatino, S.; Buccolieri, R.; Olesen, H.R.; Ketzel, M.; Berkowicz, R.; Franke, J.; Schatzmann, M.; Schlünzen, K.H.; Leitl, B.; Britter, R.; et al. COST 732 in practice: The MUST model evaluation exercise. Int. J. Environ. Poll. 2011, 44, 403-418. [CrossRef]

26. Saylor, D.J.; Georgescu, M.; Milne, J.M.; Hart, M.A. Development of national anthropogenic heating database with an extrapolation on international cities. Atmos. Environ. 2015, 118, 7-18. [CrossRef]

27. Davydov, D.K.; Belan, B.D.; Antokhin, P.N.; Antokhina, O.Y.; Antonovich, V.V.; Arshinova, V.G.; Arshinov, M.Y.; Akhlestin, A.Y.; Belan, S.B.; Dudorova, N.V.; et al. Monitoring of Atmospheric Parameters: 25 Years of the Tropospheric Ozone Research Station of the Institute of Atmospheric Optics, Siberian Branch, Russian Academy of Sciences. Atmos. Ocean. Opt. 2019, 32, 180-192. [CrossRef]

Publisher's Note: MDPI stays neutral with regard to jurisdictional claims in published maps and institutional affiliations.

(C) 2020 by the authors. Licensee MDPI, Basel, Switzerland. This article is an open access article distributed under the terms and conditions of the Creative Commons Attribution (CC BY) license (http://creativecommons.org/licenses/by/4.0/). 